\title{
24 weeks of Pilates-aerobic and educative training to improve body fat mass in elderly Serbian women
}

This article was published in the following Dove Press journal:

Clinical Interventions in Aging

28 April 2014

Number of times this article has been viewed

\author{
Anne WS Rutjes' \\ Marcello Di Nisio 2,3 \\ 'Institute of Social and Preventive \\ Medicine, University of Bern, Bern, \\ Switzerland; 'Department of Medical, \\ Oral, and Biotechnological Sciences, \\ University G D'Annunzio of Chieti- \\ Pescara, Chieti, Italy; ${ }^{3}$ Department of \\ Vascular Medicine, Academic Medical \\ Center, Amsterdam, the Netherlands
}

\section{Dear editor}

We read with interest the article by Ruiz-Montero et al, in which the authors used a before-and-after study design to examine changes in body composition (fat mass and lean body mass) related to an aerobic-Pilates program in elderly Serbian women. ${ }^{1}$ The authors concluded that "a combined program of aerobic and Pilates, carried out under the supervision of an instructor, at least twice a week, produces health benefits in functionally independent women over the age of 60 ". This conclusion is overly optimistic and not supported by the evidence provided. The authors used an uncontrolled study design so that, by definition, the observed changes in anthropometric endpoints can at best be interpreted as preliminary evidence of the effectiveness of the exercise program. Further, the evidence provided for the effectiveness of the exercise program is very weak. The authors attributed the changes in outcomes to the exercise program, but ignored the potential effect of the imposed study diet, health education, and other factors that may have independently affected the anthropometric outcomes. The endpoints chosen by the authors are surrogate outcomes, not patient relevant outcomes, so it is incorrect to refer to health benefits. With the exception of the waist-to-thigh ratio, imprecise thus not statistically significant changes were observed in muscle perimeters (ten outcomes), skinfold thickness (seven outcomes), and bone measurements (four outcomes). However, the authors inaccurately report "As for skinfold thickness, various results were obtained $(P<0.05)$ ", and fail to address the problem of multiple testing in their discussion. In contrast, the observed change in fat mass may be of interest, but the clinical relevance of the magnitude of this finding is not discussed, nor is it put in context with the imposed study diet or other confounding factors. In conclusion, the authors seem to base their conclusions on an incorrect interpretation of their data, providing yet another example for the necessity of multidisciplinary collaborations, where at least health care specialists, biostatisticians, and methodologists team up to design, conduct, and report clinically meaningful research.

\section{Disclosure}

The authors report no conflicts of interest in this communication.

\section{Reference}

1. Pedro Jesús Ruiz-Montero PJ, Castillo-Rodriguez A, Mikalački M, Nebojsa C̆, Korovljev D. 24-weeks Pilates-aerobic and educative training to improve body fat mass in elderly Serbian women. Clin Interv Aging. 2014;9:243-248. 


\section{Authors' reply}

\author{
Pedro Jesús Ruiz-Montero' \\ Alfonso Castillo-Rodriguez ${ }^{2}$ \\ Milena Mikalački ${ }^{3}$ \\ Čokorilo Nebojsa ${ }^{3}$ \\ Darinka Korovljev ${ }^{3}$
}

'Department of Physical Education and Sport, School of Sport Sciences, University of Granada, Granada, Spain; ${ }^{2}$ Faculty of Sport, University of Pablo de Olavide, Seville, Spain; ${ }^{3}$ Faculty of Sport and Physical Education, University of Novi Sad, Novi Sad, Serbia

Correspondence: Pedro Jesus Ruiz-Montero

Department of Physical Education and Sport, School of Sport Sciences, University of Granada, Carretera de Alfacar, s/n, CP I807I, Granada, Spain

Email pedrorumo@ugr.es

\section{Dear editor}

We are grateful for interest of Dr Rutjes and Dr Di Nisio in our study.

Our conclusion is designed based on results and discussion of the manuscript " 24 weeks of Pilates-aerobic and educative training to improve body fat mass in elderly Serbian women". In reference to their opinion that we were optimistic, and that this optimism was not supported by the evidence provided, we suggest you they read the scientific literature referenced in the paper, ${ }^{1-4}$ regarding the benefits of the Pilates method and aerobic exercises, in different population types (over 100).

According to our study design, it is a project with national funding, and anthropometric measurements were conducted by an ISAK II (International Society for the Advancement of Kinanthropometry) evaluator ( $<3 \%$ TEM). Likewise, Rutjes and Di Nisio suggest our evidence for the effectiveness of the exercise program was weak. We recommend they check again the tables in the paper. You can see significant differences in pre-post values of anthropometric parameters, but the most important health benefits are the increase in skeletal muscle mass, and decrease of $\%$ fat mass, in elderly people. We do not understand why Rutjes and Di Nisio write that we reported inaccurately.

We can consider that not all the results of our study are significant, because of the importance of aging process. In spite of this, we have reduced some effects of aging in participants. Do you still think our physical education program does not produce any benefits? The patient's personal motivation is important and this is the reason why we need to conduct further research to evaluate the differences of those motivation states in pre-post intervention program.

The imposed diet and health education were used as control measure, for avoiding contamination of the sample, and for producing better control of sample studied. Moreover, we have referred to studies on benefits of physical activity programs in body mass and corporal characteristics of elderly people. Similarly, discussion is based on the decrease of body fat by intervention program of physical activity even when aging increases body fat and produces sarcopenia.

Discussion and conclusion of our manuscript treated data mentioned before. Hence, we consider that we have defended correctly the results of our manuscript and some of the comments of Rutjes and Di Nisio can be subjectives.

\section{Disclosure}

The authors report no conflicts of interest in this correspondence.

\section{Reference}

1. Hayes LD, Grace FM, Sculthorpe N, et al. The effects of a formal exercise training programme on salivary hormone concentrations and body composition in previously sedentary aging men. Springerplus. 2013;2(1):18.

2. Pilates JH, Miller WJ. Pilates' Return to Life through Contrology. New York: JJ Augustin; 1945.

3. Thompson WR. Worldwide survey reveals fitness trends for 2009. ACSM's Health Fitness J. 2009;12(6):7-14.

4. Levine B, Kaplanek B, Jaffe WL. Pilates training for use in rehabilitation after total hip and knee arthroplasty: a preliminary report. Clin Orthop Relat Res. 2009;467(6):1468-1475.
Clinical Interventions in Aging

\section{Publish your work in this journal}

Clinical Interventions in Aging is an international, peer-reviewed journal focusing on evidence-based reports on the value or lack thereof of treatments intended to prevent or delay the onset of maladaptive correlates of aging in human beings. This journal is indexed on PubMed Central, MedLine, the American Chemical Society's 'Chemical Abstracts Ser-

\section{Dovepress}

vice' (CAS), Scopus and the Elsevier Bibliographic databases. The manuscript management system is completely online and includes a very quick and fair peer-review system, which is all easy to use. Visit http://www.dovepress.com/testimonials.php to read real quotes from published authors. 